\title{
Discovery of the Exquisite Meaning of the Word "chudu” in Chinese Poetry of the Adherents of a Former Dynasty
}

\author{
CAI Jin-fang \\ Chinese Department of College of Liberal Arts, Shanghai University, Shanghai, China
}

\begin{abstract}
The word “chudu” comes from Qu Yuan's Li Sao “huang lan kui yu chu du xi, zhao ci yu yi jia ming”. The original meaning was the day of birth. After the Song Dynasty, the literati began to use it to refer to birthdays. By the end of the Ming Dynasty, they had been calling their birthdays "chudu" once they celebrated it and they were so keen on birthday celebrations. Gu Yanwu pointed out that the word "chudu" only fits "the old ministers (or the exiled ministers) who lamented the crash of the Yingcapital of the country of "Chu” such as Qu Yuan. At the same time, its use in Huang Zongxi's and Wang Fuzhi's birthday poems is also consistent with this context. The unique situation and mood of the adherents led them to be close to Qu Yuan and Wen Tianxiang, which bestowed "chudu" the special meaning. It is very suitable for the ministers who suffered the crash of their Dynasties or those who were exiled distantly to express their feelings about the old dynasties and old friends. After these people, Chen Yinke consciously acknowledged this layer of interpreting "chudu” and used it, which has not only enriched the connotation of “chudu”, but also extended its cultural life. From Qu Yuan to Wen Tianxiang, until Gu Yanwu, Huang Zongxi, Wang Fuzhi, and then to Chen Yinke, we can take a glimpse of the spiritual world of the Chinese adherents of Dynasties.
\end{abstract}

Keywords: chudu, adherents, Qu Yuan, Gu Yanwu, Chen Yinke

\section{Introduction}

“Chudu” (初度) comes from Qu Yuan’s Li Sao (Encountering Sorrow) "huang lan kui yu chu du xi, zhao ci yu yi jia ming” (皇览揆余初度兮, 肇锡余以嘉名). The interpretation of this sentence by Wang Yiwas: “My fatherBoyong studied the year-month-day when I was born, he found that the sun and the moon were in the middle of heaven and earth, therefore I was given the name of beauty and kindness” ${ }^{1}$ Wang Yi interpreted "chudu" as the year-month-dayof his birth. Zhu Xistarted interpreting "chudu" as the season of one's birth. He writes: "The $d u$ in chudu actually refers to the season."2 Although the two explanations are slightly different, they are actually referring "chudu” to the days of birth. Therefore, later generations often brought up "chudu" for birthdays. In some classic poetry, we often see titles such as "The Fiftieth chudu", and "The Eightieth

\footnotetext{
[Author Information] CAI Jin-fang, female, DOB: December 1965, graduated from the Zhejiang University Ancient Books Institute in 2003. Now she is a professor and doctoral supervisor of the Chinese Department of College of Liberal Arts of Shanghai University. She has published the paper Who is Ju Gong in Chen Yinke's Poetry and To Investigate Self-Identity Hidden in Chen Yinke's Poems.

${ }^{1}$ [Han] Wang Yi, The Songs of the Chu Zhangju, Volume 1, The Affiliate Texts of the Four Collections.

2 [Song] Zhu Xi, The Songs of the Chu Jizhu, Volume 1, Shanghai Ancient Books Publishing House, 1979, p. 3.
} 
chudu". In the modern and contemporary times, a few classically cultivated literati still use the word. For example, in 1945, Xu Teli (徐特立) wrote the poem Xu Qian's Thirtieth Chudu; In 1963, Yang Liansheng (杨 联陸) wrote the poem The Forty-Nine Years Old Chudu. Of course, ancient Chinese people used to celebrate their birthdays according to “xusui” (虚岁) (i.e a person’s age is one year at birth. The age is counted as one year older than the actual years one has been born.). However, apart from its ordinary representation of birthday, the word is better used for some special people to refer to birthday. We will analyze as the following.

\section{The Gradual Process of Referring “Chudu” as Birthday by Ancient People}

According to our research, the ancients had been going through stages of development in using the word "chudu" to refer to birthdays. Until the Tang Dynasty, people had made barely any reference about "chudu" to birthdays. There was no such use in Quan Tangshi. There is one poem Zongwu's Birthday in the Poetry of Du Fu and he still used "birthday". The people of the Song Dynasty began to use "chudu". When the Song people used it, nevertheless, the word "birthday" often appeared in the titles. While in the text of poetry, the word "chudu" was often used as an allusion. For example, Wei Liaoweng's Declining the Poem by the Officials Below the Deputy to Celebrate My Birthday, writes: "I have stayed in the country of Li Sao for three years, having intoned the poetry of Li Sao and had my chudu four times already."3 The allusion of "chudu" is widely used in Su Shi's A short letter of Declining the Birthday Poem, ${ }^{4}$ Zhou Bida's A short letter of Answering the Birthday Poetry, ${ }^{5}$ Zhao Fan's Si Yuan's Birthday poem, ${ }^{6}$ etc. The exception is in the Dragon Boat Festival Chudu in Wen Tianxiang's Complete Collection of Mr. Wenshan ${ }^{7}$ that attracted our special attention. The use of "chudu" by Yuan people was basically the same as that of the Song people. When the poets of Ming Dynasty wrote poems about birthdays, we can observe growing frequency of replacing "birthdays" with "chudu" in the titles as time went by. The earlier contexts in poetry were widely known, such as Xie Qian's Congratulating Xu Shimei's Seventieth Chudu, ${ }^{8}$ Li Dongyang's On June the Ninth Chudu, ${ }^{9}$ After that, there is Li Mengyang's On Chudu Missing Yushan, ${ }^{10}$ He Jingming's two poems Chudu, ${ }^{11}$ Li Panlong's The Two Poems of Furi Zuoshi Chudu, ${ }^{12}$ Wang Shizhen's The Dazongbo Minister Dong Yongjun's Chudu. ${ }^{13}$ The practice of these poetry leaders has set up a role model for others. After them, in the poetry titles of Ming Dynasty, “Chudu” had sprung up rapidly like mushrooms. It was spoken of in almost every celebration of birthdays. From the frequent use of "chudu"and the large volumes of writings of birthday poetry, it can be inferred that the Ming Dynasty people were very keen on birthdays.

\footnotetext{
${ }^{3}$ [Song] Wei Liaoweng, Complete Works of Heshan, Volume 68, The Affiliate Texts of the Four Collections.

4 [Song] Su Shi, Complete Works of Dongpo, Volume 70, Wenyuange, Siku Quanshu.

5 [Song] Zhou Bida, Wen Zhongji, Volume 24, Siku Quanshu.

6 [Song] Zhao Fan, Chun Xi Manuscript, Volume 3, Siku Quanshu.

7 [Song] Wen Tianxiang, The Complete Works of Mr. Wenshan, Volume 14, The Affiliate Texts of the Four Collections.

8 [Ming] Xie Qian, Returning to the Field Manuscript, Volume 7, Siku Quanshu.

${ }^{9}$ [Ming] Li Dongyang, The Huai Lu Tang Collection, Volume 91, Siku Quanshu.

10 [Ming] Li Mengyang, The Kongtong Collection, Volume 32, the Qing Emperor Guangxu's Fifteenth year, the engraving collection of Weinan Yan's Family .

${ }^{11}$ [Ming] He Jingming, The Dafu Collection, Volume15, Volume 21, the Qing Emperor Qian Long's Fifteenth year, He Huishao's Ci Tang engraving version.

12 [Ming] Li Panlong, The Cangming Collection, Volume14, Siku Quanshu.

13 [Ming] Wang Shizhen, Four Manuscripts of Yanzhou, Volume 40, Siku Quanshu.
} 


\section{Gu Yanwu Reveals the Special Meaning of “Chudu”}

Facing the Ming Dynasty people's excessive emphasis on celebration of birthday and the general use of "chudu" to refer to birthdays, some people were deeply dissatisfied and put forward their own distinct views. He was the great adherent scholar Gu Yanwu ( 1613-1682) of the late Ming and early Qing dynasties. In his Ri Zhi Lu (《日知录》), Article Birthday, he writes:

The ritual of birthday ceremony, none had the ancient people. Years ago I was wandering around and boarding at the place called Jimen. Someone sent me a gift on my birthday and I replied by saying that: "It was the exiled prince of Zhou Dynasty in Shijing who started speaking of wochen (我辰), i.e my birthday; It was Qu Yuan, the exiled minister who lamented the crash of the Ying capital of the country of Chu, who started speaking of chudu (初度). Yan Shi Jia Xun states that: according to the customs of Jiangnan, the family prepares new clothes and bathing facilities and decorations for one year old babies. If the baby is a male, bows, arrows, paper and pen should be prepared. If the baby is a female, knife, rullers, needles and threads should be prepared. Food and drinks, as well as treasures should be laid in front of the children, testing whether they are greedy, frugal, wise or mentally disabled by observing their intention of grabbing the things. This process is called the test of the children. The family gathered together because of this banquet. Since then, if the two parents are still alive, there will always be food and drinks. Those who lost their father held banquets all the day and barely felt sentimental. When the Emperor Yuan of the Liang Dynasty was young, he celebrated his birthday on 6th August by promoting vegetarianism and hosting assembly to study Buddhist scriptures. Since his mother passed away, these activities also ended.' This ritual originated from the Qi Dynasty and the Liang Dynasty. During the Tang and Song Dynasties, from the emperor to the civilians, all of them have been admiring this day. They invited guests and held banquets, writing poetry and making toasts. Their practice was far from the original intention of having birthdays, which was to understand the hard work of parents raising up their children, and then better treated their parents with filial respect and make them happy. ${ }^{14}$

Gu Yanwu, mentions a letterat the beginning of the text, which refers to The Letter of Declining the Congratulations on My Birthday from Friends (《与友人辞祝书》), writes:

I saw Zide yesterday.He said that the chief of the county wanted to celebrate my birthday. It was the exiled prince of Zhou Dynasty in Shijingwho started speaking of wochen; It was Qu Yuan, the old minister who lamented the crash of the Yingcapital of the country of Chu, who started speaking of chudu.Therefore, Tang Taizong of the Tang Dynasty once wept in front of his ministers with the lecturing of upholding diligence, while recently Sun Tuigu and Zhang Kuishan of late Ming Dynasty were for the abolition of celebration of birthdays. Those who are always in the smooth circumstances, still refused to do that; Not to mention the fact that I have not had any children and my situation is different from others.I was displaced and exiled around the country, living just for the sake of remaining alive.If I were the historical figures such as Wang Hua, Wang Su, Lu Xiang, Yu Li, Wang Huilong, who were from the Wei, Jin, Southern and Northern Dynasties. For my entire life, I would wear frugal clothes and eat vegetables. Neither would I listen to any music, nor would I participate in any happy events. On the contrary, I drank with my friends on this day, and dazzled the eyes of the world. How could I not feel grieved and guilty? Those who know me may express their condolence because they understand my misfortune, rather than enforcing the formalities upon me, which were actually not rituals, against my will and also the nature. ${ }^{15}$

Gu Yanwu's attitude towards birthdays can be inferred from the above two texts. First, he did not advocate any birthday celebrations. If both parents are still alive, there are some reasons to celebrate. If one of the parents was no longer alive, neither should they celebrate the birthdays nor should they accept any birthday gifts. Everyone should understand the parents are laborious, those who are not able to serve the filial piety

\footnotetext{
${ }^{14}$ [Qing] Gu Yanwu, [Qing] Huang Yucheng’s Collection, Qi Baoqun, Lu Zongli’s edition, Ri Zhi Lu, Volume 13, Shanghai Ancient Books Publishing House, 2006, pp. 813-814.

${ }^{15}$ [Qing] Gu Yanwu, Tinglin collection of poems and essays, Anthology, Volume 3, The Affiliate Texts of the Four Collections.
} 
towards their parents should do so to a greater extent. Second, the word "chudu"cannot be used wherever a birthday is celebrated. Because this word was from Qu Yuan's Li Sao. Only "the old ministers (or the exiled ministers) who lamented the crash of the Ying capital of the country of Chu" were entitled to use this word. The word "wochen" is not applicable for any random person. Because the word came from the third chapter of the Xiaoya· Xiaobian poem in Shijing:

Seeing the mulberry trees planted by the parents, I must respectfully stand in front of the tree.

Who is not showing full of respect for the father, and who is not deeply attached to the mother?

Until now, I am not connected to the fur from the outside, and not connected with the flesh from inside.

God, you sent me to the world and where is my destiny (wochen)? ${ }^{16}$

The author of the poem was the prince Yijiu,who was expelled by the Emperor You of the Zhou Dynasty because of the rumors from Baosi, the mistress of the emperor (actually the poem was written by Yijiu's tutor on his behalf). In conclusion, it was only the exiled person such as Yijiu who was entitled to use "wochen". Gu Yanwu's argument reflects his resentment and criticism of the secular birthday culture as a literatus with strong ambitions to make accomplishments. It also reflects his strong resonance, as a remnant who had been drifting for years, to Qu Yuan's and Prince Yijiu's feelings for the lost country.

When drafting The Letter, he also wrote a poem My Fiftieth Chudu in Changping (《五十初度时在昌平》), says:

I just found out that the ambitions have become hollow and unreasonable. As a result, I accomplished nothing. Time flies, as a colt passing over a crevice. I am living this life as drifting around like a duckweed.

If you were traveling a long distance and night began to fall, there was no need to worry. I just hope that for the rest of my life, I can stand a chance to see the Yellow River becomes clean.

I often walked at the edge of the mountain and the boundaries of the country, watching the yellow pheasant flying along the mountain peaks, listening to the green horses whistling and walking through the Great Wall.

Looking around, the capital is still the capital of the old country. But is it impossible to make a contribution to the country and leave my glory in the history? ${ }^{17}$

May 28th of the first year of Emperor Kangxi (1662) was Gu Yanwu's fiftieth birthday. According to the record of forty-nine to fifty-year-old of Zhou Kezhen's Gu Yanwu Chronicle, ${ }^{18}$ Gu Yanwu went to Changping in March of this year, and to worship Emperor Chongzhen's Tomb and toured Pan Mountain, and then returned to Changping. On April 15th, Emperor Yongli was killed by Wu Sangui in Yunnan Province. On the eighth day of May, Zheng Chenggong died of illness in Taiwan. Considering the background and the contents of the verses, "hoping the Yellow River in an old man's eye look clean” and "the capital is still the capital of the old country”, Gu Yanwu uses the word "chudu" in the title of this poem from the perspective of seeing himself as an old minister of the Ming Dynasty.

\footnotetext{
${ }^{16}$ Gao Heng, The Modern Interpretations of ShiJing, Shanghai Ancient Books Publishing House, 1984, p. 293.

17 [Qing] Gu Yanwu, Tinglin Poetry Anthology, Volume 3, The Affiliate Texts of the Four Collections.

18 Zhou Kezhen, Gu Yanwu's Chronicle, Suzhou University Press, 1998, pp. 271-274.
} 


\section{The Use of the Word “Chudu”by Other Survivors in the Late Ming and Early Qing Dynasties}

In the late Ming and early Qing dynasties, although other people did not make such a clear claim as $G u$ Yanwu did, they sometimes used the word "chudu” to be highly compatible with Gu Yanwu's interpretation, such as the great scholar of remnant Huang Zongxi (1610-1695) and Wang Fuzhi (1619-1692), etc.

Let’s first look at Huang Zongxi’s The Fortieth Chudu ( 《四十初度》), reads:

Half of the fall has gone by, the Persicaria flowers are flourishing again on the edge of the pond.

My current age is only three years away from my father's age when he sacrificed for the country. (My father sacrificed himself at the age of forty-three). The only difference between My birthday and Confucius' birthday is a word of hour.

At night, rely on the pillows and listen to the rain hitting the eaves. During the day, I took a sickle and went to the high land to collect the firewood and make up the collapsed huts.

When I look around, there is sadness and tears everywhere. Where is the Western Terrace or Xitai , on which I can mourn my friends who have passed away. ${ }^{19}$

Huang Zongxi became forty years old in the mid fall of the sixth year of Emperor Shunzhi (1669). At this time, he was only five years away from the perishment of the Ming Dynasty. The king of Lu from South Ming Dynasty was in charge of the court for four years, and Emperor Yongli was in charge for three years. Although Zheng Chenggong and Zhang Huangyan were carrying out the anti-Qing battles, the news was mostly negative. On the birthday, the wind wasmourning and the rain was bewailing. Therefore, he was very emotional. He was thinking of the lost father, reminiscing about the old friends, and painfully experiencing the rectification of the old state. "mourning the old friends on the Xitai", was from the allusion of Xie Ao and Wen Tianxiang, the remnants of the late Southern Song Dynasty. Xitai, is located at the Fuchun Mountain in the west of Tonglu County, Zhejiang Province, also known as the Yanziling Fishing Platform. Eight years after Wen Tianxiang's sacrifice in the capital of the Yuan Dynasty, Xie Ao and his friends ascend Xitai to worship and show their homage, and wrote a prose Weeping on Xitai to express the pain of demolition of the country and loss of their friends. Undoubtedly, when Huang Zongxi wrote this poem using the word "chudu", he thought of Qu Yuan, and also Wen Tianxiang as well as his adherent friends. Huang Zongxi had been speaking highly of the poetry of the remnants of the Southern Song Dynasty. It is impossible that he had never read the Dragon Boat Festival Chudu by Wen Tianxiang. We can reasonably believe that his strong emotions of "the old ministers", was directly attached to Wen Tianxiang and the adherents of Southern Song dynasty.

WenTianxiang’s The Dragon Boat Festival Chudu (《端午初度》), including two poems , the first poem reads:

Why complain if I die for what deserved my death? Today is my birthday and only I know about that.

My mindset at this moment is very similar to the wanderer described in poem Didu, and I can't bear chanting poem Liao'e. $^{20}$

\footnotetext{
19 [Qing] Huang Zongxi, The Nanlei Collection, the first of Nanlei Shili, The Affiliate Texts of the Four Collections.

20 Shijing Tang Feng Didu (枤杜), describes the feelings of a lonely wanderer. Shijing Xiaoya Liao'e (蓼莪), describes that the dutiful son lamented the hard work of his parents, and he suffered great pain for losing his parents.
} 
Life is like a dream lasting a hundred years, and the loneliness makes me longing for a conversation with the nobles one thousand years ago.

I am now like the prisoner of Chu who is unable to forget my home country. Today is my birthday, and a glass of water is better than the fine wine of the heavenly palace. ${ }^{21}$

The second poem reads:

For a long time, I am like a crane under the pine tree, but where am I living today, under whose roof?

In my dream, I could see that the water tumbling in the fountain of the precious jade. But when I woke up, I could only see the gloomy cloud of Yulei Mountain like Du Fu did.

I thought more about how to die the way it deserves, and it was pointless to worry about how to survive alone.

It is sighing that if the Dragon Boat Festival Iris sanguinea has feelings, facing the smoke of the land in the hometown, it also ages. ${ }^{22}$

At the same time, Wen Tianxiang wrote another long poem Birthday, reads:

After handing in the weapon to the enemy, I became a prisoner and was taken to the tent of the Yuan Army, then a prison with nothing but the empty air.

Although my heart was burning, I was dignified and staunch in front of the enemy. I am willing to sacrifice, even if I die in a boiling pot of oil.

Life and death have already been doomed already. How can glories or humiliations make my heart beat?

It had never occurred to me that I could see the eucalyptus growing green leaves for four times when imprisoned.

My appearance faded away, and grey hair emerged as time went by.

The old days were like a mixture of reality and illusion, just like the story of the deer hiding under the banana tree. ${ }^{23}$

The undeserved reputation is like a firefly in the grass that only glimmers in a blink of the eye.

The grievances and sorrows inside are written in theMetaphysical language. Speaking of “chudu”, I was particularly impressed by Qu Yuan’s Li Sao.

I traveled to the wonderland, knocked on the door of Penglai fairyland in the morning, and arrived at Furong City where my deceased friends live in the evening.

Inadvertently I am back to my home country, which made me feel very disturbed.

I was desperate to see the hometown people, but it was impossible. I could not help bursting into tears. ${ }^{24}$

Wen Tianxiang was born on the second day of the fifth lunar month of the the third Duanping Year of Emperor Li of the Song Dynasty (6th June, 1236). This day is only three days away from the Dragon Boat Festival that commemorates Qu Yuan. Therefore, Wen named the poem The Dragon Boat Festival Chudu. On this special day, Wen, who was imprisoned in the capital of the Yuan Dynasty, was deeply touched by Qu Yuan and his Li Sao. Wen and Qu Yuan resonated with each other across hundreds of years in between. He also

${ }^{21}$ [Song] Wen Tianxiang, The Complete Works of Mr. Wenshan, Volume 14, The Affiliate Texts of the Four Collections.

22 [Song] Wen Tianxiang, Complete Works of Mr. Wenshan, Volume 14, The Affiliate Texts of the Four Collections.

${ }^{23}$ The Story of the Deer Hiding Under the Banana Tree, from the Lie Zi, Volume 3, the Chapter of King Mu of the Zhou Dynasty, Siku Quanshu.

${ }^{24}$ Wen Tianxiang, Complete Works of Mr. Wenshan, Volume 14, The Affiliate Texts of the Four Collections. 
absorbed spiritual power from Qu Yuan. He made a metaphor of himself as the prisoner of Chu, despite of his infinitely loneliness and hopelessness, he still loved his homeland and people as deeply as Qu Yuan did. Wen Tianxiang's integrity and spirit nourished the later Chinese generations, and there is no Chinese who does not know his name. For the remnants who survived the turbulence of late Ming and early Qing dynasties, they were so closely attached to Wen Tianxiang. Huang Zongxi was a case in point, and so was Wang Fuzhi.

Wang Fuzhi had Chudu Feelings (《初度感怀》), including four poems. The first reads:

The slanting wind and rain passed over the barren hills. For fifteen years, I was living like the prisoner of the Chu State, who had never forgot the homeland.

There is still a slight trace of my soul remaining in dying, and what I could only remember was the years of the old country.

The Second reads:

One hundred and five thousand and three hundred and three days, I was surrounded by gloom like a spring silkworm everyday.

There is no one in this remote and isolated place, and I could only spoke to rain about my poverty and loneliness.

The Third reads:

I should have died eleven years ago, but I didn't die. This is not what a loyal minister should do for his glory and loyalty to the country.

Looking at the withered trees that gradually faded in the wind and rain, and listening to the humming sound of the Zigui bird, I truly betrayed not only the country, but also my parents.( Zigui means that the sons should go back home.)

The Fourth reads:

In the past ten years, many of my friends had passed away and became new ghosts. My tears were running out like rivers.

Only the white beard and the white hair on my head are my companions in the endless loneliness. ${ }^{25}$

The poem of Wang Fuzhi was written in the 18th year of Shunzhi (1661) on the first day of September and it was his forty-third birthday, only one year earlier than the $G u$ Yanwu poem we discussed earlier. In the first lunar month of this year, Emperor Shunzhi died of chickenpox, and the eight-year-old Xuanye, took the throne. In March, the accidents of Suzhou Crying Temple took place. In June, the case of pleading for cancellation of the official titles of the national official candidates in Jiangnan (江南) burst out. In August, Zheng Chenggong took over Taiwan. In September, Wu Sangui led the Qing army into Myanmar to hunt for the South Ming Dynasty Emperor Yongli. At this time, Wang Fuzhi could not see any hope of recovery of the Ming Dynasty. His living situation was like a dying prisoner who was abandoned in the obsolete hills, but it was only deeply rooted in his heart the feelings for his homeland and his old friends. His situation was in fact very similar to the situation when Wen Tianxiang wrote The Dragon Boat Festival Chudu. Wang Fuzhi once imitated the poems of Wen Tianxiang. When he was writing the Chudu Feelings, he was in the same mindset with Qu Yuan and Wen Tianxiang.

${ }^{25}$ [Qing] Wang Fuzhi, Fifty Self-edited Manuscripts, Jiangzhai collection of poems and essays, The Affiliate Texts of the Four Collections. 
It can be seen that when Wen Tianxiang and the three great scholars used the word "chudu" from Qu Yuan's Li Sao, their understanding of this wordas for its literal and emotional meaning was basically the same. In their birthday poems, we can read the deep feelings of Qu Yuan's "the old ministers who lamented the crash of the Ying capital of the country of Chu”. This layer of meaning beneath the surface implied by "chudu"was clearly revealed by Gu Yanwu, which can also beattributed to the special situation and mood of the remnants. It is not an easy task to comprehend this meaning from the word simply for those who have been living in a peaceful and comfortable environment.

\section{The Modern Scholar Chen Yinke's Voluntary Acceptance of The meaning of "Chudu”}

After the three great scholars, it is worth to mention the contribution of Chen Yinke, whose use of the word "chudu" is accompanied consciously and clearly with the sub-context of "the old ministers (or the exiled ministers) who lamented the crash of the Ying capital of the country of Chu”. In The Collection of Chen Yinke's Poetry, there are five titles on birthdays. Except for in the first Three Gorgeous Items on My Fifty-six-year-old Birthday (May 17th, the mid summer of the Year of Yiyou) (《五十六岁生日三绝》), ${ }^{26}$ he used the word "birthday". This poem was written in Chengdu in 1945. The rest of the four titles utilized the word "chudu".

The second poem, At the Age of 56 Chudu in Chengdu, Writes "I Sincerely Hope That the Country Will Be Peaceful and My Eyesight Can Become Normal Again, So That the Whole Family Can Support Each Other and Return to Our Hometown Through the Three Gorges”, On My 62nd Birthday in Guangzhou In the Year Xinmao, the Words Above Suddenly Came to Me, so I Wrote This Poem to Xiao Ying (《……辛印寓广州六十 二岁生日 $\cdots \cdots . . . \gg)$, including two poems. The First reads:

During the seven years of the Anti-Japanese War, I was displaced and my vision was deteriorating. The little wishes years ago were no longer in my mind.

From now on, I will settle down in Guangzhou, and close the door during the day to write poems of the Tao Yuanming style at home.

The Second reads:

I am resolved to read up the literature and to do research despite of the illness, with my wife's company under the light in the study room.

If this can last forever, what else is there to be pursued in this world? ${ }^{27}$

This poem can be seen as the poet's transition of replacing "birthday" with "chudu”. The poem was written on June 21st, 1951. Two and a half years ago, the poet left Peking in December 1948 and went south to Lingnan University in Guangzhou. One year and a half ago, New China was established. From the two poems, Chen Yinke had no hope for his eyesight recovery and their returning to Beijing. He had made up his mind to live in Guangzhou for a long time, and would follow the steps of Tao Yuanming, to become a hermit at the transition of dynasties, and to safeguard his integrity. To some extent, he had the intention of exiling himself in Guangzhou.

${ }^{26}$ Chen Meiyan, Chen Yinke's Collection, Poetry Collection, Beijing Sanlian Bookstore, 2001, p. 43.

27 Chen Meiyan, Chen Yinke's Collection, Poetry Collection, Sanlian Bookstore, 2001, p. 80. 
The third poem, At the Age of 67 Chudu In the Year Bingshen, Xiaoying Prepared Wine for me, and This is the Reward to Her (《丙申六十七岁初度, 晓䒯置酒为寿, 赋此酬谢》), reads:

The red clouds and green sea were the background for the tall buildings, and the blind man is having his 67th birthday today.

My wife prepared a banquet for my birthday, and her credit for writing down the manuscript for me under the lamp on weekdays could entitle her a glorious title. ( I am interpreting the poems of Hedong Jun at this moment.)

The knowledge that I have learned this life seems to be useful only in burying my old bones. I would be decapitated if the poems written in my old years were leaked out.

Fortunately, there is a lady who shares my soul, We have lived in this hot southern region for eight years. ${ }^{28}$

This poem was written in 1956, and it has been eight years since the poet came to Guangzhou. The verse of "decapitated " in the third phrase has clearly revealed the poet's attitude towards the current regime and the ruling party. The poet once said: "I was born as the citizen of the empire Qing, and die as a ghost of communism”. He saw himself as a loyal minister and an exiled person.

Mr. Zhang Shizhao read this poem about a month later and rewardhim another poem, from which we can get some confirmation. The following paragraph is quoted from Hu Wenhui's The Interpretation of Chen Yinke’s Poetry, says: “In August 1956, Zhang Shizhao was entrusted by Mao Zedong, and went to Hong Kong from Beijing for a visit aiming for the unification of the military. When he passed through Guangzhou, Zhang paid a special visit to Chen. They had a joyful conversation together, and he granted Chen two poems. One of them is titled Chen gave me recent works as gifts, The Discussions on Eternal Happiness was especially outstanding and I would like to thank him with this long prose. The second poem was The Work Composed with Yinque's At the Age of 67 chudu, Xiaoying Prepared Wine for me, and This is the Reward to Her (《和寅恪 <六 七初度谢晓䒯置酒 > 之作》), says:

For more than eight years,. We are aged quite a lot and went through radical changes of life. But you insist on the study of history, just like the blind Zuo Qiu Ming, whose knowledge eventually overwhelmed Gongyang.

Like what Wang Anshi’s poem wrote, we are old friends who have been knowing each other since we were students. Your current academic achievement has been recognized throughout the country.

I came to see you after you recited the poem of"chudu”.From my perspective, you are the same as Qu Yuan, who is unwilling to flatter the king of Chu.

Your wife is able to write wonderful calligraphy and she is the best partner to help you keep a record of your manuscripts. May your couple stay in harmony and enjoy life. ${ }^{29}$

Although Hu Wenhui quoted Zhang Shizhao's poetry, he did not seem to fully understand the poems of Chen and Zhang. So he added: "At the Chudu of Age of 67, Chen was born in 1890, and the 67 years old was the xusui according to the Chinese tradition. The birthday was called 'chudu', which means entering into the age. "30 Although his interpretation of "chudu” was not wrong, strictly speaking, his understanding of the word remained the literal surface because of his ignorance of the source of it. With Mr. Zhang Shizhao's capabilities

${ }^{28}$ Chen Meiyan, Chen Yinke’s Collection, Poetry Collection, Sanlian Bookstore, 2001, p. 122.

${ }^{29}$ Hu Wenhui, The Interpretation of Chen Yinke's Poems, Guangdong People's Publishing House, 2008, p. 648.

${ }^{30} \mathrm{Hu}$ Wenhui, The Interpretation of Chen Yinke's Poems, Guangdong People's Publishing House, 2008, p. 648. 
in reading the classic literature, he could reach the meaning of "chudu" in Chen's poems within a glimpse of an eye. The third phrase of Zhang's poem not only compares Chen directly to Qu Yuan, but also highly appreciates the ancient style of Chen, which is the unwillingness to please the supreme ruler. This refers that Chen refused to go to Beijing to take up the Director of the Research Institute of History of the Chinese Academy of Sciences. It can be concluded that the use of the word "chudu" in Chen's poetry is indeed to show that although he was in a new society, his thoughts were left in the old times as the old ministers and exiled ones. (This poem is recorded in the first chapter of The Biography of Liu Rushi, titled At the Age of 67 Birthday, Xiaoying Prepared Wine for me, and This is the Reward to Her. ${ }^{31}$ Chen did not use "chudu" here and wrote "birthday" instead. It was very plausible that Chen used "birthday" earlier, but later changed to"chudu"when selected in The Collection of Chen Yinke's Poetry. This reflects Chen's considerations on the use of "chudu").

Chen's fourth poem was titled On July 3rd of the Solar Calendar in the Year of Dingyou, At the Age of Sixty-Eight Chudu,I Happen To Be Ill , The Book Titled The Interpretation and Textual Criticism of the Poetry of Qian and Liu's Marriage Had not Yet Finished, and the Date of Publishing was Unknown, therefore I would like to write a prose for my feelings (《丁酉阳历七月三日, 六十八岁初度, 适在病中, 时撰 <钱柳姻缘诗 释证 > 尚未成书, 更不知何日可以刊布也, 感赋一律》), writes:

The birthday coincides with the illness.My life is full of worries, and it has been four years since I began the textual criticism and interpretation of poetry.

There is hardly any match for Qian Qianyi’s profound knowledge, and the uniqueness of Liu Rushi's taste and style.

After the demolition of the Ming Dynasty, Qian Qianyi became another person,while Liu Rushi was flowerly like tender and bright.The couple were committed to reviving the Ming Dynasty, and ended up with nothing, falling in the liquors to relieve the sorrow.

The water in the wells of Chengtian Temple should be carefully cherished. Only there is the place where books can be safely kept. ${ }^{32}$

This poem was written in July 1957. Chen's works were not able to be published because Chen's ideology was considered very conservative and backward at the time. Hecould only follow the example of Zheng Sixiao ,the survivor of the Southern Song Dynasty, and find a safe place to preserve his work of Heart History properly. ${ }^{33}$ These words, though very helpless and sorrowful,were the proof of adhering to the identity of the remnants,and validation ofthe word "chudu".

The fifth poem, On May 17th in the Year of Jiachen, Seventy-five Years Old Chudu (《甲辰五月十七日, 七十五岁初度, 感赋》), reads:

I have lived to the age of seventy, and I feel that it was very embarrassing because I have wasted most of it, not to mention today I am already 75 years old.

The past 100 years, like a board of chess with an undecided outcome. How will the world evolve next?

\footnotetext{
${ }^{31}$ Chen Yinke, The Biography of Liu Rushi, Sanlian Bookstore, 2001, p. 6.

32 Chen Meiyan, Chen Yinke's Collection, Poetry Collection, Sanlian Bookstore, 2001, p. 128.

33 Chengtian Temple, in Suzhou, Zheng Sixiao, once put his book Heart History into the iron box and sank it to the bottom of the well.It was not discovered until the end of the Ming Dynasty.
} 
The hot spring of Guangzhou has come to an end, but the flowers are still bright and beautiful. The sea is suffocating and the rain is more.

The birds of the Country of Yue are from the south and they only inhabited on the branches of the south.Which makes people feel infinitely sorrowful.I am singing sad songs alone and breaking the saliva can. ${ }^{34}$

This poem was written in June 1964. Chen was seventy-five years old.He started writing The Biography of Liu Rushi in 1954 and sealed the manuscripts in 1964. He had been writing the book for ten years. Chen said to himself that "the history of the late Ming and early Qing dynasties was grieving, and the emotions to the new events and that of the old events are combined". The book also accommodates too many of Chen's own emotional sustenance, hence at the moment the manuscript was finished, it was also the end of Chen's heart history. Meanwhile, the birthday came, and Chen became more emotional. Judging from the poem, Chen still held a wait-and-see attitude and skepticism about the fate of the new regime.When he lamented the shattering of Qian and Liu'swish. He was deeply sentimentally attached to his old root like the bird. Chenwas a very knowledgeable and confident historian. His perspective on the fate of the new regime, rather than blindness,was the reflection on his strengthened embodiment of the remnant consciousness.

The idea of Chen using the word "chudu" to reveal his feelings for "the old ministers (or the exiled ministers) who lamented the crash of the Ying capital of the country of Chu”, was deeply related to his preparation of writing The Biography of Liu Rushi. He had been reading about the works of many literati in the late Ming and early Qing dynasties, including Gu Yanwu, Huang Zongxi, Wang Fuzhi, etc. It was the interpretation of the word "chudu" given by Gu Yanwu and others that had enriched the spiritual world of Chen as a remnant.Furthermore, Chen's acknowledgement and use of the meaning of "chudu" not only enriched its connotation but also extended its cultural life. Strictly speaking, Chen was neither a old minister nor an exiled one. He was actually a "self-exiled person". We know from him that self-exiles also fit the word"chudu". By the way, Chen's father, Chen Sanli, instead of "chudu", still used "birthday" when writing birthday poems. There are certain traces in Chen's poems, demonstrating imitations to his old man, but at this point he had his own considerations.

\section{Conclusion}

The word “chudu” comes from Qu Yuan’s Li Sao “huang lan kui yu chu du xi, zhao ci yu yi jia ming”. The original meaning was the day of birth. After the Song Dynasty, the literati began to use it to refer to birthdays. By the end of the Ming Dynasty, they had been calling their birthdays "chudu” once they celebrated it. Gu Yanwu, as the great scholar of the adherents during the transition of the late Ming Dynasty and the early Qing Dynasty, and a literatus, had strong passion for the world. He was deeply dissatisfied with the obsession of celebrating the birthday, and universal practice of using "chudu" to refer to birthday. Therefore he pointed out that the word "chudu" only fits "the old ministers (or the exiled ministers) who lamented the crash of the Ying capital of the country of "Chu" such as Qu Yuan. At the same time, its use in Huang Zongxi's and Wang Fuzhi's birthday poems is also consistent with this context. The unique situation and mood of the adherents led them to be close to Qu Yuan and Wen Tianxiang, which bestowed "chudu” the special meaning. It is very suitable for the ministers

${ }^{34}$ Chen Meiyan, Chen Yinke’s Collection, Poetry Collection, Sanlian Bookstore, 2001, p. 154. 
who suffered the crash of their Dynasties or those who were exiled distantly to express their feelings about the old dynasties and old friends. After these people, Chen Yinke consciously acknowledged this layer of interpreting "chudu" and used it several times. From that we can take a glimpse of Chen Yinke's unique spiritual world of the adherent in New China period.

Upon writing the closing of this paper, I occasionally read an article by Mr. Ge Zhaoguang, titled Rereading Yang Liansheng's Diary—Because it is not so solemn, it is more interesting, which mentions that Mr. Yang Liansheng once wrote a poem Forty-Nine Years Old chudu that seems to be relevant to the main theme of this paper. I transcribed it hereinafter, as the conclusion. Mr. Ge writes:

After all, the Chinese scholars in foreign countries seem little repressed despite of the "Masters" among them, which can be seen in Yang Liansheng's poetry. When he had his birthday in July 1963, he wrote a poem Forty-Nine Years Old chudu, says:

Study abroad with only a book box. How could I know that I had been staying in a foreign country for such a long time. Other people's ridicule is inevitable,and I can only relieve this stress with my career of teaching.

Two years later, he wrote another quatrain phrase Sense Time in July, says:

A scholar who stays overseas, what he can bring to his country after all? He has not yet accomplished anything, and already has grey hair at his temples.

Although he enjoyed a peaceful environment and immunity from the political waves of domestic anti-right movements, famine, Siqing and Cultural Revolution, he still felt living under the roof of someone else. He was not alone.Xiao Gongquan was in the same situation. In Yang Liansheng's diary of February 1976, nearly eighty-year-old Xiao ongquan sent him a poem Sitting Upright Alone, says:

Will God still allow us to return home with company? It seems that it is impossible this life,but to look forward to the next life.

Reading the words, Yang Liansheng couldn't help but burst into tears. The diary writes that he picked up the phone and talked to Mr. Yu Yingshi about this matter. He couldn’t help but cry again. ${ }^{35}$

Chudu, the self-exiled person, sentimentally attached to the old country, were connected together here by Mr. Yang Liansheng, who knew Chen Yinke very well.

\section{References}

[Han] Wang, Y. (1919-1936). The Songs of the Chu Zhangju (Vol. 1). The Affiliate Texts of the Four Collections. Shanghai:The Commercial Press.

[Song] Su, S. (2003). Complete Works of Dongpo (Vol. 70). Wenyuange, Siku Quanshu. Shanghai: Shanghai Ancient Books Publishing House.

[Song] Wei, L. W. (1919-1936). Complete Works of Heshan (Vol. 68). The Affiliate Texts of the Four Collections. Shanghai: The Commercial Press.

[Song] Wen, T. X. (1919-1936). Complete works of Mr. Wenshan (Vol. 14). The Affiliate Texts of the Four Collections. Shanghai: The Commercial Press.

[Song] Wen, T. X. (1919-1936). The Complete Works of Mr. Wenshan (Vol. 14). The Affiliate Texts of the Four Collections. Shanghai: The Commercial Press.

[Song] Zhao, F. (2003). Chun Xi Manuscript (Vol. 3). Siku Quanshu. Shanghai: Shanghai Ancient Books Publishing House.

${ }^{35}$ Ge Zhaoguang, Rereading Yang Liansheng's Diary-Because it is not so solemn, it is more interesting, News Network, November 9, 2014. 
[Song] Zhou, B. D. (2003). Wen Zhongji (Vol. 24). Siku Quanshu. Shanghai: Shanghai Ancient Books Publishing House.

[Song] Zhu, X. (1979). The Songs of the Chu Jizhu (Vol. 1). Shanghai: Shanghai Ancient Books Publishing House.

[Ming] He, J. M. (the Qing Emperor Qian Long’ s Fifteenth year, 1750). The Dafu Collection (Vol. 15, 21). Xinyang:He Huishao’s Ci Tang engraving version.

[Ming] Li, D. Y. (2003). The Huai Lu Tang Collection (Vol. 91). Siku Quanshu. Shanghai: Shanghai Ancient Books Publishing House.

[Ming] Li, M. Y. (the Qing Emperor Guangxu’s Fifteenth year, 1889). The Kongtong Collection (Vol. 32). Weinan :The engraving collection of Weinan Yan's Family.

[Ming] Li, P. L. (2003). The Cangming Collection (Vol. 14). Siku Quanshu. Shanghai Ancient Books Publishing House.

[Ming] Wang, S. Z. (2003). Four Manuscripts of Yanzhou (Vol. 40). Siku Quanshu. Shanghai Ancient Books Publishing House.

[Ming] Xie, Q. (2003). Returning to the Field Manuscript (Vol. 7). Siku Quanshu. Shanghai Ancient Books Publishing House.

[Qing] Gu, Y. W. (1919-1936). Tinglin collection of poems and essays, Anthology (Vol. 3). The Affiliate Texts of the Four Collections. Shanghai: The Commercial Press.

[Qing] Gu, Y. W. (1919-1936). Tinglin Poetry Anthology (Vol. 3). The Affiliate Texts of the Four Collections. Shanghai: The Commercial Press.

[Qing] Gu, Y. W. (2006). Huang Yucheng’s Collection. In B. Q. Qi and Z. L. Lu (Eds.), Ri Zhi Lu (Vol. 13). Shanghai: Shanghai Ancient Books Publishing House.

[Qing] Huang, Z. X. (1919-1936). The Nanlei Collection, the first of Nanlei Shili. The Affiliate Texts of the Four Collections. Shanghai: The Commercial Press.

[Qing] Wang, F. Z. (1919-1936). Fifty Self-edited Manuscripts, Jiangzhai collection of poems and essays. The Affiliate Texts of the Four Collections. Shanghai: The Commercial Press.

Gao, H. (1984). The modern interpretations of ShiJing. Shanghai: Shanghai Ancient Books Publishing House.

Zhou, K. Z. (1998). Gu Yanwu’s chronicle. Suzhou: Suzhou University Press.

Chen, Y. K. (2001). The Biography of Liu Rushi. Beijing: Sanlian Bookstore.

Chen, M. Y. (2001). Chen Yinke's Collection, Poetry Collection. Beijing: Sanlian Bookstore.

Hu, W. H. (2008). The interpretation of Chen Yinke's poems. Guangzhou: Guangdong People’s Publishing House

Ge, Z. G. (2014). Rereading Yang Liansheng's Diary-Because it is not so solemn, it is more interesting. Pengpai News Network, November 9. 